knowledge, no theory." Role-playing games are not, how ever, to everyone's liking. Jiri Friml, who leads a group of 11 people at the Centre for Plant Molecular Biology at the University of Tübingen, Germany, expected more practical solutions rather than group action, although he positively acknowledged that the course concentrated on the problems and issues that young group leaders typically face.

A II of this takes time, of course: managing and caring for peoplekeeping them happy, as Mocsai put it-writing grants and papers, teaching, and taking care of administrative work all nibble away at valuable time that could be spent at the bench. "All these things were vying for their time and they were spending too much time with management issues," Franko said. Time and project management are therefore increasingly important tools for group leaders who often work at the bench themselves. The HHMI/BWF course gives due space to this topic; in addition to the usual solutions, such as defining priorities or using project management software to organize research, it also aims to teach people how to say 'no' or just to close the office door. Equally important, it stresses improving group members' time-management skills by setting clear goals and deadlines or by simply encouraging them to adhere to fixed agendas and timelines.

Given the demand and the overwhelmingly positive feedback that $\mathrm{HHMI} / \mathrm{BWF}$ received from course participants-even established scientists expressed interest-it is reasonable to ask whether some of these skills, such as time and project management or conflict resolution, should be taught at the university level. However, "not everyone will be in this situation," Behrens cautioned, so it would make more sense to teach these skills to scientists at the postdoc level rather than spending valuable time earlier in the university curriculum. Similarly, Franko pointed out that their courses focus on those who need these skills most, right before or after they start their first research group. "We've chosen the group we think are the most receptive," she said.

\section{... it is reasonable to ask whether some of these skills, such astime and project management or conflict resolution, should be taught at the university level}

W hat is equally clear is that a course here and there is not enough to meet demand. "We had 120 [participants] last time-that's not even a drop in the bucket," Franko said. Furthermore, it is not the responsibility of funding organizations to run such courses, she added, but of the whole academic system. Although she acknowledged that some topics, such as mentoring or conflict resolution, would be best handled by professional teachers, topics such as time management or budgeting could easily be taught by staff from a research institute. This would also make courses even more appealing to young researchers. "We found out from the participants that they want to hear [about these topics] from other scientists," Franko said. "The scientists say the same things but only they can put it into the context of day-to-day experience." To this end, $\mathrm{HHMI}$ and BW F are now partnering with academic institutions, learned societies and other funding organizations to start lab management courses at their own institutions. This will involve sharing resources, such as teaching materials or instructors, and learning from each other about what works and what does not.

\section{... skills such as leadership, social competence and conflict resolution are essential for every successful project leader}

But it is probably most important to create awareness among the research community that skills such as leadership, social competence and conflict resolution are essential for every successful project leader. "If we convince these people how important this stuff is, they will hopefully give their postdocs time to take these courses. ... It's not that H HMI and BW F do this to make their fellows more competitive," Franko stressed. "Everyone needs this type of training and everyone needs to jump in and share their resources."

\section{Hdger Breithaupt}

doi:10.1038/sj.embor.7400387

\title{
Understanding consciousness
}

\section{Theraceis on to decipher the human mind, but it will taketimeto accommodate the cultural repercussions of this knowledge}

. H Hanif Kureishi's short novel The Body, Adam is a playwright in his sixties who looks back on his life with a fair amount of regret (Kureishi, 2002). Ralph, an admirer of Adam's work, introduces him to an experiment that could offer a new lease of life. With the help of a confident doctor from a dubious but apparently sophisticated clinic, Adam is given the chance to have his mind transferred into the corpse of an unknown man. He simply goes shopping for a new body off the rack, undergoes a mysterious operation at a sterile facility and finds himself in a fresh and younger body that he will inhabit for a sixmonth trial period. Adam enjoys the immediate consequences of his younger appearance, travels all over Europe, takes pleasure in various adventures and indulges in mindless sexual encounters. For some time, he feels as if he is finally living the life he never had. But Adam soon realizes that changing his body did not give him the privilege of escaping his mind.

\section{It would bea mistake to claim that consciousness is exclusively an observable behaviour...}

The reader does not know whether Adam merely had his brain transplanted into the new body or whether his whole 'self' was somehow wired onto the young 
man's brain, but the story highlights the age-old question of what is the repository for subjective consciousness and phenomenal experience. Kureishi's novel evokes the old dualism between flesh and spirit, body and mind, which runs deep through Western culture. But now that neuroscience is able to explain human nature and the mind in increasing detail, this dualism may soon be-or indeed, should bedead and buried. Adam's story, although fictional and futuristic, prompts ethical considerations of progress in neuroscience research and offers us the chance to envisage future paradoxical scenarios that such progress might produce.

$\mathrm{F}$ or a long time, consciousness has been the subject of neuroscience, psychology, philosophy, cognitive science and other disciplines in the natural and social sciences and the humanities. John Searle, Professor of the Philosophy of $\mathrm{M}$ ind and Language at the University of California, Berkeley (USA), claimed that, of the various fields of research focusing on consciousness, the one that "is most likely to have important long-term results is neurobiology, where the race to solve the problem of consciousness is now on" (Searle, 2005). But consciousness is hard to define, and no single definition is apt. Common sense would describe consciousness as "those states of sentience and awareness that typically begin when we awake from a dreamless sleep and continue until we go to sleep again, or fall into a coma or die or otherwise become "unconscious'" (Searle, 1995). The Oxford English Dictionary defines consciousness more philosophically as "the state or faculty of being conscious, as a condition and concomitant of all thought, feeling and volition".

What is clear, however, is that consciousness is formed by external stimuli, to which we are exposed throughout lifewhen we taste wine, recognize a face, get stung by a bee, look at the sea or listen to a Beethoven cello sonata. All of these events trigger a sequence of processes that we experience as coherent, inner and subjective states of sentience called qualia- a key term in consciousness studies. The core problem in the study of consciousness is the understanding of how such stimuli affect our brain and how measurable brain phenomena and metabolism are translated into experience. The problem is intriguing and challenging because our subjective experience is not only perceptual as in the cases mentioned above, but also uses inner processes, such as worrying about paying the telephone bill on time, deciding on the future and feeling love for someone. For neuroscientists, consciousness is thus located in the individual organism, namely the brain. In the tradition of the humanities and social theory, however, consciousness is also the product of subjectivity and inter-subjectivity in a historical contexta fusion of cognition, reason, emotion and intentionality.

What neuroscientist Vilayanur $\mathrm{S}$. Ramachandran, Director of the Center for Brain and Cognition at the University of California, San Diego (USA), calls the "single most important problem in science" is grasping the entirely personal and private affair that is the phenomenal experience, through an objective and causal thirdperson account. Some believe that this will never be possible and that the complexity of the mind and consciousness is not amenable to the third-person observations that are common in other branches of the natural sciences. But as Antonio Damasio, Head of the Department of Neurology at the U niversity of lowa (lowa City, USA) noted, "although the investigation [of consciousness] is condemned to some indirectness, this limitation is not restricted to consciousness. It applies to all cognitive phenomena" (D amasio, 1999).

F or evolutionary psychologists and materialists, the problem of the mind is solved by considering it to be "a machine, nothing but the on-board computer of a robot made of tissue" (Pinker, 1997). Similarly, Daniel Dennett, Director of the Center for Cognitive Studies at Tufts University (M edford, M A, USA) denies the existence of qualia and claims that consciousness is an illusion or an epiphenomenon. "Human consciousness [...] can best be understood as the operation of a [... virtual machine implemented in the parallel architecture of a brain that was not designed for any such activities. The powers of this virtual machine vastly enhance the underlying powers of the organic hardware on which it runs..." (D ennett, 1991). Although it may seem that we experience the world through a 'self' that is located somewhere in our heads and that we collect and absorb subjective experiences from the external world through our senses, it is an illusion that this type of awareness is posited in any non-material factor or process. Consequently, it should be possible to seek and understand the material basis of consciousness.

\section{... if the meansto influence consciousness became available, human subjectivity could be manipulated, with theinevitable risk of creating different classes of states of mind...}

According to Christof Koch, a professor at the California Institute of Technology (Pasadena, USA) whose work focuses on visual perception, consciousness of things takes place at an intermediate level between the material objects of the external world and internal thoughts and feelings. Because the latter dimensions are considered totally inaccessible to human inquiry, many aspects of high-level cognition, such as decision-making, are beyond the bounds of awareness. Instead, these operations are carried out by something perceived as a non-conscious homunculus that resides in the forebrain: "you are not directly conscious of your thoughts. You are conscious only of a representation of these in terms of sensory qualities, particular visual imagery, and inner speech" (Koch, 2004).

Because different consciousnesses exist, it is worth trying to acknowledge different epistemologies and to become aware of the limits of each of the discourses (Rose, 2004). It would be a mistake to claim that consciousness is exclusively an observable behaviour and to leave out the real existence of subjective qualitative states of awareness or deny the biological basis of those states. To investigate this complex phenomenon, the parallel and collaborative efforts of philosophers, psychologists, cognitive scientists and neurobiologists are required (Searle, 2005). In other words, both the internal and external views of consciousness are needed.

Q uestioning the real existence of qualia, the biological basis of consciousness and the nature of our perceptions and subjective experiences raises fundamental philosophical questions, which can lead beyond the point of no return. O f equal interest and concern is how disquieting it would be if scientists came to understand the most sophisticated mind riddles and deciphered the neural correlates of consciousness. 

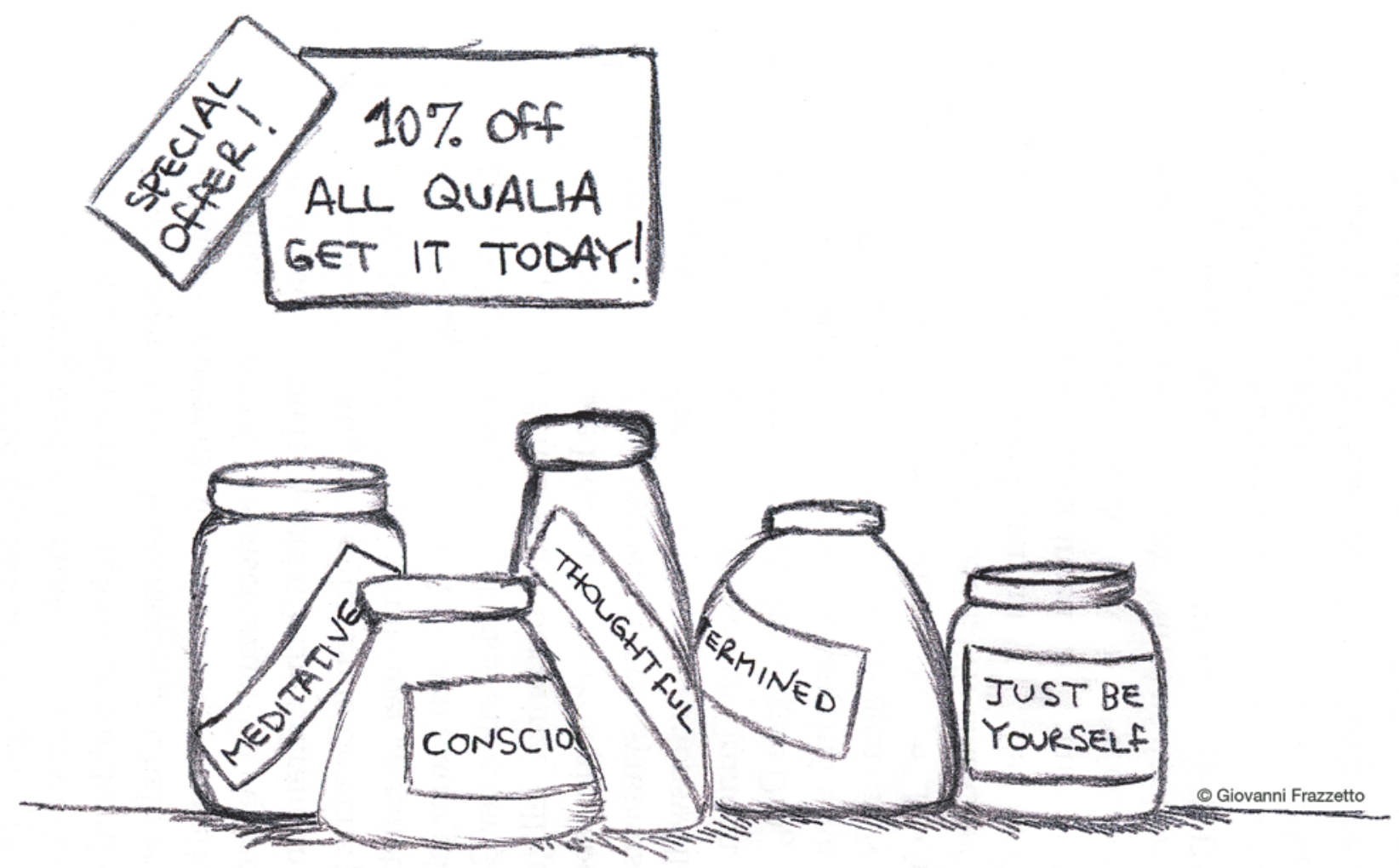

$\mathrm{N}$ euroscience has undoubtedly made rapid progress in the elucidation of brain function in recent years. This knowledge has been translated into technology in the expanding field of psychopharmacology, which now gives us the means to interfere with pathologies and deficits and to alter mental states-be they cognitive or emotional-by manipulating the chemistry of the brain (Rose, 2002; Wolpe, 2002; Farah et al, 2004; Hall, 2004). Would it be worrying if it became possible to extend the application of this type of neurotechnology to all types of mental state and to the most inner states of consciousness?

Thomas Metzinger's concern over the need for "ethics of consciousness" is particularly relevant here (Metzinger, 2003). Metzinger, Professor of Philosophy at the University of $M$ ainz in Germany, recognizes the emotional price we must pay for an increased understanding of consciousness. Challenges to previously unquestioned visions of our 'self' lead to a kind of 'discomfort'. In addition, if the means to influence consciousness became available, human subjectivity could be manipulated, with the inevitable risk of creating different classes of states of mind-desirable or disagreeable, legal or despicable, decent or uncivil.
Kureishi's novel is helpful in envisaging such scenarios. Adam agrees to be transferred into a new body because he is not satisfied with his life and age and would like to have a second chance. After suffering occasional incompatibilities with his new body and difficulties in coping with the circumstances surrounding his new appearance, Adam desires-again-to 'live less' in his mind. Perhaps a technology of consciousness might satisfy an individual's desire, similar to that of Adam, to achieve different states of mind at different stages of life. Or it might allow humans to adjust their bodies to the exigencies of the life to which they aspire, or allow them to choose which mental states they would like to take to the grave, irrespective of the rest of their life, memories and experiences. Expanding this visionary horizon, one day we might understand the chemical basis of consciousness to the extent that it will be possible to ask the pharmacist for a drug to steer consciousness at

\section{... if thequest for the identification and understanding of human consciousnessis successful, this knowledge will inevitably prompt a cultural renewal of the vision of man...}

will and reach a desired state of mind. If we knew precisely which parts and processes of the brain needed to be activated to reach an appropriately thoughtful state to better reflect on our lives, it would no longer be necessary to seek an isolated spot in a park or meditate for hours in search of inspiration. A pill might do the trick.

A II this sounds quite visionary. Adam's mind transplant is still fictional, although it is amusing to find dubious Internet sites that offer brain transplants and the chance to start a brand new life. Regardless of whether a sophisticated technology of consciousness might be attractive to some individuals or alarming to others, it is not yet available. It is important, how ever, to recognize that if the quest for the identification and understanding of human consciousness is successful, this knowledge will inevitably prompt a cultural renewal of the vision of man, and of subjectivity and inner perspective, that will need to be analysed by different disciplines. As Ralph, the man who introduces Adam to the mind transplant, says: "the thinking in this area has yet to be done- just as there has been argument over abortion, genetic engineering, cloning and organ transplant, or any other medical advance, so there will be over this." 


\section{REFEREN CES}

Damasio AR (1999) The Feeling of What H appens: Body and Emotion in the Making of Consciousness. N ew York, NY, U SA: H arcourt Brace

Dennett D (1991) Consciousness Explained. Boston, MA, USA: Little, Brown \& Co.

Farah MJ, Illes J, Cook-D eegan R, Gardner H, Kandel E, King P, Parens E, Sahakian B, Wolpe PR (2004) N eurocognitive enhancement: what can we do and what should we do? $N$ at Rev Neurosci 5: 421-425

Hall W (2004) Feeling 'better than well'. EM BO Rep 5: 1105-1109

Koch C (2004) The Q uest for Consciousness: A N eurobiological Approach. Denver, CO, USA: Roberts \& Co

Kureishi H (2002) The Body: and Seven Stories. London, U K: Faber \& Faber

Metzinger T (2003) Der Begriff einer

Bewusstseinskultur. In Kaiser G (ed), Year Book 2002/2003 of the Wissenschaftszentrums N ordrhein-Westfalen pp 150-171. Düsseldorf,
Germany: Wissenschaftszentrum N ordrheinWestfalen

Pinker S (1997) H ow the Mind Works. N ew York, NY, USA: N orton

Rose H (2004) Consciousness and the limits of neurobiology. In Rees D, Rose S (eds), The $\mathrm{N} \mathrm{ew}$ Brain Sciences: Perils and Prospects pp 59-70. Cambridge, U K: Cambridge U niversity Press

Rose S (2002) 'Smart drugs': Do they work? Are they ethical? Will they be legal? $N$ at Rev Neurosci 3: 975-979

Searle JR (1995) The mystery of consciousness. NY Rev Books N ov 2. www.nybooks.com Searle JR (2005) Consciousness: what we still don't know. NY Rev Books Jan 13 www.nybooks.com

Wolpe PR (2002)Treatment, enhancement, and the ethics of neurotherapeutics. Brain Cogn 50: 387-395

\section{Giovanni Frazzetto}

doi:10.1038/sj.embor.7400384

\title{
The consequence of errors
}

\author{
From memory molecules to the criminal chromosome, erroneous \\ conclusions continueto blight scientific research
}

A ncient Greek philosophers laid the groundwork for the scientific tradition of critical inquiry, but they nevertheless missed out on one aspect important to modern science. Many philosophers obtained their results through a tradition of contemplation and thought rather than experimental procedure, which, not surprisingly, led to errors. Aristotle's belief that the brain is a cooling organ for the blood was definitely not based on anything that scientists today would consider scientific evidence. He also thought that in humans, goats and pigs, males have more teeth than females, a notion easy enough to correct. $\mathrm{H}$ is statement that flies have four legs was repeated in natural history texts for more than a thousand years despite the fact that a little counting would have proven otherwise.

Today, these errors are anecdotal, and science prides itself on having progressed from intuition-driven to solid, experimentbased reasoning. But modern science is not as infallible as it seems-it has erred in the recent past and still does today.
To err is human. Given the increasing influence of science on nearly all aspects of daily life, the important question is how efficiently such errors are recognized and corrected.

$\mathrm{T}$ he basis of every experiment is the acquisition of data. But even if this merely involves counting, it can be astonishingly difficult to obtain reliable data. In the 1950s and 1960s-centuries after the number of fly legs and male teeth had been corrected-James M cConnell at Ann Arbor University (MI, USA) carried out experiments to condition planarians to associate a light stimulus with an electric shock so they would scrunch up their bodies in response to light. The educated worm was then ground up and fed to untrained littermates. Once they had cannibalized their brethren, these worms learned to contract in response to light twice as fast as compared with controls, according to McConnell. He concluded that the conditioned memory was stored in a molecule that could be transferred by ingestion (Rose, 1993). Today, we know that memory is not transferable in this way. But the implications of McConnell's experiment-that specific memories are stored in isolatable molecules-caused quite a stir at the time. "Eat your professor", the New York Times suggested (Zankl, 2004), and TIME Magazine discussed potential misuses, such as a police state or government brainwashing a whole population by lacing tap water.

\section{... modern science is not as infallible as it seems - it has erred in the recent past and still does today}

After several groups reproduced the experiments in worms and mammals and achieved the same results, the idea of memory transfer was well established. Questions finally arose from researchers who found it hard to train flatworms, let alone transfer trained behaviour through cannibalism. A fierce discussion followed. Potential confounding factors cited by 'successful' worm trainers included water temperature, time of day, phase of the moon, the direction the worm was heading when the electric shock was applied, or the slime trails it left behind. M cConnell himself advised those who attempted to teach planarians to "keep changing the experimental situation until the right conditions are hit" (Travis, 1981). In the end, it was probably background variations-worms spontaneously contract in response to strong light-that facilitated self-deception to such an extent that wishful thinking prevailed.

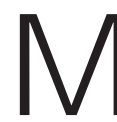
ajor errors also occurred when scientists, carried away by their discoveries, designed experiments to confirm their hypotheses and omitted the usual controls. In 1965, when the technology to visualize chromosomes had just been developed, a study was carried out to test for chromosome abnormalities among men in an institution for dangerous criminals. Among the 196 men studied, 8 showed a duplicated $Y$ chromosome (Jacobs et al, 1965). This seemed to be extraordinarily high, so the researchers deduced from the small sample that XYY men tend to become criminals-although nobody had bothered to determine the 